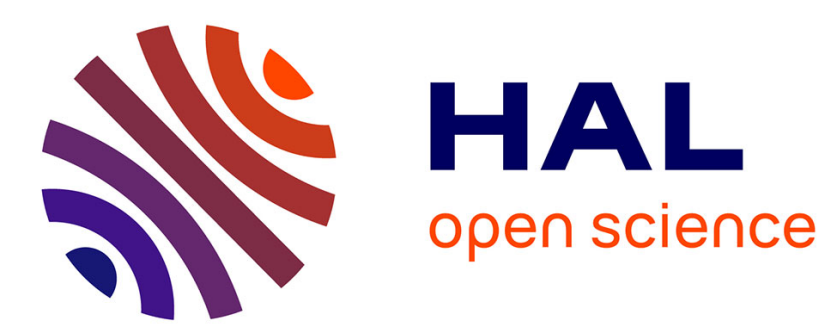

\title{
Patient specific stress and rupture analysis of ascending thoracic aneurysms
}

Olfa Trabelsi, Frances M. Davis, Ambroise Duprey, Jose F. Rodriguez-Matas, Stéphane Avril

\section{- To cite this version:}

Olfa Trabelsi, Frances M. Davis, Ambroise Duprey, Jose F. Rodriguez-Matas, Stéphane Avril. Patient specific stress and rupture analysis of ascending thoracic aneurysms. Journal of Biomechanics, 2015, 10.1016/j.jbiomech.2015.04.035 . hal-01276411

\section{HAL Id: hal-01276411 \\ https://hal.science/hal-01276411}

Submitted on 19 Feb 2016

HAL is a multi-disciplinary open access archive for the deposit and dissemination of scientific research documents, whether they are published or not. The documents may come from teaching and research institutions in France or abroad, or from public or private research centers.
L'archive ouverte pluridisciplinaire HAL, est destinée au dépôt et à la diffusion de documents scientifiques de niveau recherche, publiés ou non, émanant des établissements d'enseignement et de recherche français ou étrangers, des laboratoires publics ou privés. 


\section{Patient specific stress and rupture analysis of ascending thoracic aneurysms}

Olfa Trabelsi ${ }^{1}$, Frances M. Davis ${ }^{1}$, Ambroise Duprey ${ }^{1,2}$, Jose F Rodriguez-Matas ${ }^{3}$, Stéphane Avril ${ }^{1}$

${ }^{1}$ Center for Biomedical and Healthcare Engineering, Ecole Nationale Supérieure des Mines de SaintEtienne, CIS-EMSE, CNRS:UMR5146, LCG, Saint Etienne, France.

${ }^{2}$ Hôpital Nord, Cardiovascular Surgery Service, CHU de Saint Etienne, F-42055 Saint-Etienne, France.

${ }^{3}$ Mechanical Engineering Department, Aragón Institute of Engineering Research (I3A), Universidad de Zaragoza, Zaragoza, Spain 


\section{ABSTRACT}

An ascending thoracic aortic aneurysm (ATAA) is a serious medical condition which, more often than not, requires surgery. Aneurysm diameter is the primary clinical criterion for determining when surgical intervention is necessary. However, biomechanical studies have shown that the peak wall stress is a much better indicator of patient rupture risk for other types of aneurysms. In this manuscript, a method for obtaining the patient specific wall stress distribution of the ATAA and the retrospective rupture risk for each patient is presented. Five human ATAAs were obtained during elective surgeries to replace each patient's aneurysm with a synthetic graft. In addition, the preoperative ECG-gated dynamic CT scans for each patient were provided. The material properties and rupture stresses for each tissue sample were identified by performing bulge inflation tests. The dynamic CT scans were used to generate patient specific geometries for a finite element model of each patient's aneurysm. The material properties from the bulge inflation tests were implemented in the finite element model and the wall stress distribution at four different pressures was estimated. Three different rupture risk indices were compared: diameter, rupture risk, and overpressure. The wall stress distribution in the ATAA was complex. The peak wall stress ranged from $28-94 \%$ of the rupture stress of the sample. The rupture risk and overpressure indices were both only weakly correlated with diameter $(\rho=-0.29$, both cases). In addition, the results revealed a path towards the non-invasive identification of patient specific material properties directly from the dynamic CT images. In the future we plan to conduct a large experimental and computational study that includes asymptomatic patients under surveillance, patients undergoing elective surgery, and patients that have experienced rupture or dissection to determine if peak wall stress, the rupture risk index, or maximum diameter can meaningfully differentiate between the groups.

Keywords: Ascending thoracic aortic aneurysm, Finite element analysis, Wall stress, Rupture risk, Aneurysm rupture, Patient specific material properties

Word count: 3099 


\section{Introduction}

Ascending thoracic aortic aneurysms (ATAA) are a localized ballooning of the aorta. Approximately 30,000 people in Europe and 15,000 people in the United States are diagnosed with an ATAA each year (Johansson et al., 1995; Ramanath et al., 2009). Early detection of ATAAs is hampered by the fact that most ATAAs are asymptomatic and are only detected as incidental findings during the investigation of other conditions. Patient treatment is focused on timely surgery since spontaneous rupture or dissection is almost always fatal (Chau and Elefteriades, 2013; Coady et al., 1999; Davies et al., 2002; Juvonen et al., 1997). Surgical intervention is indicated for ATAAs with diameters larger than $5.5 \mathrm{~cm}$ or for fast growing aneurysms (> $0.15 \mathrm{~cm}$ per year) (Chau and Elefteriades, 2013; Coady et al., 1999, 1997). Since the standard approach for ATAA repair is open heart surgery, resection continues to be challenging (Martufi et al., 2014). The majority of patients with an ATAA are elderly further increasing the risk of surgical complications (Ramanath et al., 2009). Ideally, the optimal time for surgical intervention would be determined on a patient specific basis by identifying when the risk of aneurysm rupture or dissection exceeds the risk of surgical complications.

The broad guideline given by the maximum diameter criterion is insufficient for developing patient specific risk assessments. The diameter criterion of $5.5 \mathrm{~cm}$ for ATAAs was developed by studying the incidence of dissection and rupture in a large population. Consequently, patients with aneurysms smaller than $5.5 \mathrm{~cm}$ still have a 5-10\% chance of experiencing aneurysm rupture, aneurysm dissection, or death (Chau and Elefteriades, 2013; Coady et al., 1999; Elefteriades and Farkas, 2010). Possibly more insidious, even at $6 \mathrm{~cm}$ only $31 \%$ of patients have experienced complications suggesting that many large aneurysms are resected that might have remained stable for the patient's lifetime (Chau and Elefteriades, 2013; Polzer et al., 2013; Sundt, 2013). To move towards the ideal case of patient specific risk assessments, several biomechanical criteria have been explored for aortic aneurysms including wall stress (Fillinger et al., 2003; Gasser et al., 2010; Raut et al., 2013a; Vande Geest et al., 2006a), over-pressure (Martin et al., 2013), and non-diameter shape based criteria (Lee et al., 2013; 
Raut et al., 2013a; Shum et al., 2011) . In fact, for abdominal aortic aneurysms, the peak wall stress was shown to estimate patient risk with a higher accuracy, sensitivity, and specificity than the diameter criterion alone (Fillinger et al., 2003). However to the authors' knowledge there have been no studies comparing the efficacy of biomechanical criteria and the diameter criterion for ATAAs.

The objective of this study is to demonstrate a methodology where the wall stress distributions and retrospective rupture indices for several ATAAs are generated on a patient specific basis. The study includes five patients who underwent elective surgery to have their ATAAs removed. To develop accurate models of the wall stress distribution and estimates of rupture risk the: (1) patient specific geometry, (2) patient specific material properties, (3) patient specific rupture stresses, and (4) physiological forces acting on the aneurysm wall must be known. In this study, we used bulge inflation tests to characterize the material properties and rupture stresses of the human ATAAs (Davis et al., 2015; Marra et al., 2006; Romo et al., 2014). These mechanical properties were then implemented in a finite element code to find each patient's wall stress distribution. From the wall stress distributions, each patient's rupture risk at the time of surgical intervention was estimated retrospectively. Two biomechanical criteria, the rupture risk index and the overpressure index, were compared to the clinical criterion of maximum aneurysm diameter to evaluate the efficacy of the biomechanical criteria.

\section{Experimental Study}

\subsection{Donor Tissue Collection}

ATAA specimens and pre-operative ECG-gated dynamic CT scans were obtained from five patients undergoing elective surgery for ATAA repair at the University Hospital Center of St. Etienne (CHU) between December 2012 and March 2013. Patient records were reviewed to obtain demographic data, medical history, and blood pressure information. The relevant demographic information and medical history for each of the five patients is listed in Table 1. The specimens were stored in saline solution at 
$4^{\circ} \mathrm{C}$ until mechanical testing occurred. Immediately before testing, the thickness of each ATAA was measured at 5 locations using calipers; the average thickness for each patient is reported in Table 1 . The provided CT scans were later used to reconstruct the patient specific geometries in the finite element model (Sec. 3.1). The Institutional Review Board of CHU approved the use of human tissue and all data collection in this study.

\subsection{Mechanical Testing}

All mechanical testing was performed within 72 hours of the surgical intervention. The tissue sections were dissected and tested according to our previously published protocol (Romo et al., 2014). Briefly, a $45 \mathrm{~mm}$ square sample was cut from the greater curvature of each ATAA specimen and clamped in a bulge inflation device. During the bulge inflation test, water at a constant rate was injected by pushing a piston pump at $15 \mathrm{~mm} / \mathrm{min}$ until the tissue ruptured (Figure 1). Simultaneously, the pressure was measured using a digital manometer (WIKA, DG-10) and images were recorded using a commercial stereo-digital image correlation (DIC) system (GOM, 5M LT). The collected images were analyzed using ARAMIS (GOM, v. 6. 2.0) to measure the three dimensional displacement of the tissue surface. From the displacement data, the Green-Lagrange strain was computed. The Cauchy stress was found using the inverse membrane approach (Romo et al., 2014). The biaxial failure stress for each ATAA was determined from the stress-strain data. Table 2 lists the mean value of the maximum principal stress for each patient and the number of specimens that were ruptured.

\subsection{Patient Specific Material Properties}

To aid in the selection of an appropriate material model, co-axiality tests were run on the stress-strain data. For an isotropic material the Cauchy-Green tensor, $\mathbf{C}$, and the second Piola-Kirchhoff stress, $\mathbf{S}$, must be coaxial. This requires: $\mathbf{e}=\mathbf{S C}-\mathbf{C S}=\mathbf{0}$ (Zhao et al., 2009). Due to the measurement errors, $\mathbf{e}$ will not be exactly zero even if the material is truly isotropic. To measure the degree of co-axiality, the following relationship was used 


$$
\varepsilon=\frac{2\left|e_{12}\right|}{\sqrt{(\mathbf{S C}):(\mathbf{C S})}}
$$

where values of $\varepsilon$ near zero indicate the stress and strain are nearly coaxial. The map of the coaxiality indicator for each patient can be found in the Appendix (Fig. S1) and the mean value of the co-axiality indicator for each patient is presented in Table 2.

\section{Constitutive model}

The Demiray constitutive model (Demiray, 1972) was chosen to describe the elastic response of the ATAA :

$$
W=\kappa(J-1)^{2}+D_{1}\left(e^{D_{2}\left(\overline{I_{1}}-3\right)}-1\right)
$$

where the deformation gradient, $\mathbf{F}=J^{1 / 3} \mathbf{I} \overline{\mathbf{F}}$, has been decomposed into its dilatational and isochoric parts and $\overline{\boldsymbol{C}}=\overline{\mathbf{F}}^{\mathrm{T}} \overline{\mathbf{F}}$ is the modified right Cauchy-Green tensor. The strain energy depends on the local volume ratio, $J=\operatorname{det}(\boldsymbol{F})$, and $\overline{I_{1}}=\operatorname{tr} \overline{\mathbf{C}}$. In Eq. (2), the parameter $\mathrm{D}_{1}$ has units of stress, $\mathrm{D}_{2}$ is a dimensionless strain stiffening parameter, and $\kappa$ is the compressibility modulus. According to Eq. (2), the initial stiffness of the tissue is $E_{0}=2 D_{1} D_{2}$. The second Piola-Kirchhoff stress is then given by:

$$
\begin{aligned}
\mathrm{S} & =2 \frac{\partial W}{\partial C} \\
& =2 \kappa \mathrm{J}(\mathrm{J}-1) \mathbf{C}^{-1}+\mathrm{J}^{-2 / 3}\left(\mathbb{I}-\frac{1}{3} \mathbf{C}^{-1} \otimes \mathbf{C}\right):\left(2 \mathrm{D}_{1} \mathrm{D}_{2} \mathrm{e}^{\mathrm{D}_{2}\left(\overline{\mathrm{I}_{1}}-3\right)}\right) \mathbf{I} .
\end{aligned}
$$

where $\mathbb{I}$ is the fourth order identity tensor.

The value of the model parameter $\kappa$ was set to $1 \mathrm{GPa}$ to approximate the nearly incompressible response of the ATAA (Carew et al., 1968; Riveros et al., 2013). Minimizing the sum of the squares difference between the experimental stresses and those calculated using Eq. (4), the values of the two remaining parameters, $D_{1}$ and $D_{2}$, were identified. The nonlinear minimization was solved in MATLAB (Mathworks, v. 7.14) where the model parameters were constrained to be positive. One 
should note that the stress-strain reconstruction method that was used identifies the stress and strain locally at 1203 subdomains (Romo et al., 2014). The co-axiality criterion is used to determine the subdomains where the principal directions of the Cauchy stress tensor (principal stresses $\sigma_{1}$ and $\sigma_{2}$ ) are aligned with the principal directions of the right Cauchy-Green tensor (principal stretches $\lambda_{1}$ and $\lambda_{2}$ ). For those points, the Demiray model is used to predict locally the values of $\bar{\sigma}_{1}$ and $\bar{\sigma}_{2}$ from $\lambda_{I}$ and $\lambda_{\mathrm{II}}$ and then the experimental values of $\sigma_{\mathrm{I}}$ and $\sigma_{\mathrm{II}}$ are compared to their predictions $\bar{\sigma}_{\mathrm{I}}$ and $\bar{\sigma}_{\mathrm{II}}$ obtained with the Demiray model. When the model and prediction were not in agreement $\left(\mathrm{R}^{2}<0.8\right)$ the subdomain was discarded. The stress-strain curves in the remaining subdomains where the value of $\varepsilon$ was less than 0.1 (Fig. S1) were used to identify the average material parameters. In general, these requirements led the boundary of the specimens to be excluded from the parameter identification. The mean values of the material parameters are presented in Table 2 .

\section{Computational Study}

\subsection{Image Acquisition and 3D Reconstruction}

For each patient, ECG-gated dynamic CT scans were processed to reconstruct the aneurysm geometry in diastole and systole. CHU provided CT DICOM images of ten phases during the cardiac cycle (resolution: $512 \times 512$, slice thickness $=0.5 \mathrm{~mm}$ ). The lumen of the aneurysm is clearly visible in the DICOM files (Figure 2a), but detection of the aneurysm surface was not possible automatically. A non-automatic segmentation of the CT image slices was performed using MIMICS (v. 10.01, Materialise NV). The three-dimensional surface of the aorta in each phase was identified (Figure 2c) and then the aneurysm was isolated from the remainder of the aorta (Figure 2d). Since the thickness of the ATAA could not be discerned from the CT images, the thickness of the aneurysm was assumed to be constant and equal to the value measured ex vivo for each patient (Table 1). To identify the diastolic and systolic phases, the luminal volume for each phase was calculated (Figure 6). Systole was defined as the phase with the largest volume and diastole as the phase with the smallest volume (Figure 2e). The diastolic surface was exported to create the finite element model. 
Rhinoceros (v.X.X , Robert McNeel \& Associates), ANSYS ICEM (v.X.X , Ansys Inc.) and ABAQUS (v.X.X , Dassault Systèmes Inc.) were used to construct the three dimensional finite element mesh. For all of the patients the finite element mesh was composed of hybrid hexahedral structured elements (C3D8H). Each model had approximately 40,000 elements and 120,000 nodes.

\subsection{Zero-Pressure Geometry}

The patient specific geometries for the ATAA model were generated from medical images where the aneurysm was under pressure. To accurately determine the wall stress distribution in the finite element model, the zero-pressure geometry must be identified. In this study, the zero-pressure geometry is also taken as the zero-stress configuration; any residual stresses that may exist in zeropressure configuration are ignored. A diastolic pressure of $80 \mathrm{mmHg}(10.67 \mathrm{kPa})$ was used for all five patients. Starting from the pressurized diastolic geometry, the zero-pressure geometry was calculated using the pull-back algorithm developed by Riveros et al. (Riveros et al., 2013). The zero pressure geometries identified for each patient have been included in the Appendix (Fig. S2).

\subsection{Numerical Simulation \& Data Analysis}

ABAQUS was used to analyze the deformation and stress distributions in the ATAA models. To evaluate the behavior of the ATAA as the blood pressure increases, luminal pressures of $15,30,45$, and $60 \mathrm{kPa}(120-450 \mathrm{mmHg})$ were applied to each ATAA. Note that the pressure varies from 1 to 3 times physiological pressure. The shear stress induced by blood flow was not considered in this analysis as previous studies have found that these stresses have a negligible effect on the overall stress analysis (Peattie et al., 2004, 1996; Vorp, 2007). The zero-pressure geometry found for each patient was used as the initial configuration. The patient specific material parameters found in the experimental study (Table 2) were implemented in ABAQUS using the user subroutine UHYPER. At the inlet and outlet of the aneurysm only radial displacement was permitted.

Once the stress analysis was complete the biomechanical rupture risk indicators for each patient were determined. The rupture risk index was calculated by dividing the peak wall stress from the pressure 
simulation at systolic blood pressure by the experimentally measured rupture stress (Table 2). An overpressure index was also found by dividing the patient's normal systolic pressure by the luminal pressure necessary to reach the rupture stress. For both indices as the value of the index approaches 1 the risk of rupture increases. The maximum diameter criterion was normalized by the cut-off value of $55 \mathrm{~mm}$ to provide a diameter index that ranges between approximately 0 and 1 . Linear correlations between the different rupture risk indicators were quantified using Pearson's linear correlation coefficient, $\rho$.

\section{Results}

\subsection{Comparison between FEM and CT Systolic Volume}

To assess the accuracy of the computational model, the systolic volume measured from the CT images was compared with the systolic volume predicted by the finite element model. For Patients 1-4, a normal systolic pressure of $16 \mathrm{kPa}(120 \mathrm{mmHg})$ was used. Since Patient 5 suffered from hypertension, the highest systolic blood pressure recorded in the month prior to surgical intervention was used ( $23 \mathrm{kPa}, 174 \mathrm{mmHg})$. Figure 3 shows the percent change in volume measured from the CT reconstruction and the predicted percent volume change obtained from the FE simulation. Overall, the predicted and measured volume changes are in good agreement. The values of the diastolic and systolic volumes measured from the CT together with the volume predicted by the finite element simulations can be found in the Appendix (Table S1). The volume change of the arterial lumen between diastole and systole is directly influenced by the mechanical properties of the arterial wall and the pressure change. The good agreement between the FEM and CT values for the volume change between diastole and systole suggests that the material properties reported in Table 2 are a reasonable approximation of the in vivo arterial compliance for each patient.

\subsection{Patient Specific Stress Analysis}

For all of the patients, the principal stress distributions for an applied luminal pressure of $15 \mathrm{kPa}$ are shown in Figure 4. Artificial stress concentrations occur at the inlet and outlet of the aneurysm due to 
the constraints at the boundary so the five outermost rings of elements near the aneurysm inlet and outlet have been removed. In Figure 4, only the central region of the aneurysm is shown. The peak wall stress for Patients $1-5$ were $783,652,438,601$, and $412 \mathrm{kPa}$, respectively, after neglecting the boundary effects. The maximum principal stress was located on the inner curvature of the aneurysm for every patient. For Patients 1, 3, and 4 multiple regions of high stress concentrations are visible on the inner curvature. The stress maps of the principal stress at the other simulated pressures $(30,45$, and $60 \mathrm{kPa}$ ) were similar and can be found in the Appendix (Figs. S4-S7).

The peak wall stresses identified for each of the patients was loosely correlated with the maximum diameter of the aneurysm as shown in Fig. $4 \mathrm{f}(\rho=0.53)$. As the diameter of the aneurysm increased, the peak wall stress also increased. However, Patient 2 had the largest aneurysm $\left(\mathrm{d}_{\max }=55 \mathrm{~mm}\right)$ (Fig. 4b) but, did not have the largest peak wall stress. Patients 1 and 4 (Fig. 4a and 4c) had the same maximum diameter $(55 \mathrm{~mm})$ but different peak wall stresses (Patient 1: $783 \mathrm{kPa}$, Patient 4: $601 \mathrm{kPa}$ ). The difference in peak wall stress between Patients 1 and 4 shows the impact of the local geometry and patient specific material properties on the wall stress.

Although the peak wall stress appears to be correlated with the diameter, the retrospective rupture indices were not $\left(\rho_{\text {RuptureRisk }}=\rho_{\text {Overpressure }}-0.29\right)$. Two factors led to this change: taking into account the hypertension of Patient 5 and the use of each patient's true rupture stress (Table 2). In fact, for our data set, the smallest aneurysm (Patient 5) had the highest rupture risk. In Figure 5, the rupture index for Patient 5 was calculated twice. The first, labeled 5, takes into account the actual systolic blood pressure $(174 \mathrm{mmHg}$ ) of the patient. The second, labeled $5 \mathrm{~b}$, assumes that Patient 5 has a normal systolic blood pressure of $120 \mathrm{mmHg}$. Hypertension is a well-known risk factor for aneurysm rupture and, as expected, assuming a normal blood pressure for a hypertensive patient severely underestimates his rupture risk. Also of note, the rupture risk index and overpressure were highly correlated ( $\rho=0.999)$ indicating that the indices are not independent.

\section{Discussion}


In this study, a methodology to perform patient specific stress analysis and retrospective rupture risk analysis on the ATAA was presented. Using patient specific material parameters, rupture stresses, and geometries, the wall stress distribution for five patients undergoing elective repair of their ATAA was computed. The wall stress distribution in the ATAA was complex and the peak wall stress was between $28 \%$ and $94 \%$ of the ATAA's failure strength. For all of the aneurysms, the peak wall stress was located in the inner curvature. Similar to the results reported for abdominal aortic aneurysms (AAA), the peak wall stress was loosely correlated with maximum aneurysm diameter (Fillinger et al., 2003; Truijers et al., 2007). However, for the ATAA the biomechanical indices were not correlated with the maximum diameter $(\rho=-0.30)$ indicating that a more robust set of criteria is needed.

In the experimental study, we used bulge inflation tests to characterize the material properties. Bulge inflation tests were selected because they induce a biaxial state of stress and can be used to identify the biaxial rupture stress. Furthermore, the use of biaxial testing has been shown to better reveal the nonlinear mechanical response of aneurysms (Vande Geest et al., 2006b). Unfortunately, we had three samples that ruptured at the border of the test device. For these samples (Patients 4 and 5) the rupture stress reported in Table 2 likely underestimates the true rupture stress of the aneurysm. These samples were included in the study because the border rupture does not influence the identification of the elastic material properties. The rupture stress for Patient 4 of $2.33 \mathrm{MPa}$ was significantly higher than for any of the other patients. Due to the sample's high strength, Patient 4 had a very lower rupture risk of 0.28 even though his peak wall stress was relatively high $(656 \mathrm{kPa})$. This is a significant case which strongly contradicts the diameter criterion and the rupture risk would only be lowered by identifying the true rupture stress. Patient 5 was included in the study to provide an example of the importance of using patient specific blood pressures. The knowledge that Patient 5 suffered from hypertension significantly changed the results (Fig. 5). It is true that the uncertainty about their true rupture stress does make Patient 5's rupture risk more difficult to ascertain but, it does not alter conclusion that rupture risk estimates must consider the patient specific blood pressure for hypertensive patients. 
The methodology to estimate the wall stress and retrospective rupture risk hinges on the quality of the experimental data used to run the finite element simulations. The patient specific geometry, material properties, and boundary conditions for the finite element model must be known with sufficient accuracy to calculate the rupture risk indicators. While each of these factors plays a role in precision of the wall stress calculation, it is generally accepted that an accurate geometry is the most important. Other investigators have performed sensitivity studies to evaluate the effect of assuming constant thickness (Raut et al., 2013b; Shang et al., 2013), different degrees of material nonlinearity (Polzer et al., 2013; Reeps et al., 2010), patient specific material properties (Doyle et al., 2013; Polzer et al., 2013). By far the use of patient specific material properties along with the use of a nonlinear material model has the greatest impact changing the peak wall stress by $70-170 \%$. The implementation of a non-uniform thickness however only effects the peak wall stress by approximately $20 \%$ (Raut et al., 2013b).

Two different biomechanical indices were compared to the maximum diameter criteria, the rupture risk index and the overpressure index. Neither the rupture risk index nor the overpressure index was strongly correlated with the maximum diameter ( $\rho=-0.29$, both cases) but, the risk index and the overpressure index were very strongly correlated to one another $\rho=0.999$. These results suggest that the overpressure index and risk index are not independent measures of risk. The predicted overpressure values in this study were significantly smaller $(205 \pm 60 \mathrm{mmHg})$ than the values found by Martin et al. of $553 \pm 234 \mathrm{mmHg}$ (Martin et al., 2013) although both studies used patients undergoing elective ATAA repair. In fact, the overpressure values found in our study are physiologically possible during exercise or in emotionally stressful situation for every patient except Patient 4. Further studies must be performed on a larger population of patients to understand how to translate the rupture risk index or overpressure index into a clinical understanding of patient risk.

Despite the small size of the study population, a clear trend was observed between the volume variation and the mechanical parameters. Figure 6 shows how the relative volume changed during the cardiac cycle. For Patients 2 and 3 who had small volume variations, the values of $D_{2}$ were high and the values of $D_{1}$ were relatively low. Based on these observations, we believe that the material 
properties could be iteratively identified using the objective function developed by Martínez- Martínez et al. (Martínez-Martínez et al., 2013) called the geometric similarity function. The iterative process would involve: assigning a set of material properties to the ATAA, identifying the zero pressure geometry, and then inflating the ATAA to systolic pressure. Using the geometric similarity function, the agreement between the systolic geometry computed with the finite element method would be compared with the systolic geometry obtained from the dynamic CT images. Based on the value of the geometric similarity function, the material properties would be updated until the geometry predicted by the (FE) simulation matched the systolic geometry in the CT images. This finding is particularly significant because it implies that the material parameters could be estimated on a patient specific basis using an already established clinical imaging technique.

There are several limitations to this study. The wall thickness, mechanical properties, and failure strength of the aneurysm were considered uniform. The regional variation in the wall thickness could not be identified from the dynamic CT scan and the use of a constant thickness may cause the wall stress to be underestimated. Experimental measurements indicate that the outer curvature of the ATAA is thinner than the inner curvature (Duprey et al., 2010) and that local variations in the thickness do occur (Choudhury et al., 2009; Iliopoulos et al., 2009a, 2009b). If there are regions where the wall is locally thin, the location of peak wall stress may have been incorrectly identified in our simulation. In addition, investigators have shown that the material properties in the ATAA are heterogeneous (Choudhury et al., 2009; Davis et al., 2015; Duprey et al., 2010; Iliopoulos et al., 2009a, 2009b; Romo et al., 2014). Large changes in the wall stiffness would significantly affect the wall stress calculations. Recent studies also indicate that the failure strength of the aneurysm varies with location (Iliopoulos et al., 2009a, 2009b), meaning that the location of maximum stress may not be the location of rupture (Romo et al., 2014). It remains unclear if our ability to account for the heterogeneous nature of the ATAA significantly hampers our ability to develop accurate rupture risk assessments. Additional computational and experimental studies are needed to quantify the impact of heterogeneity on the wall stress predictions. 
In addition, our sample size was too small $(n=5)$ to do meaningful statistics and a more robust population study is necessary to confirm our observations. The larger study will include asymptomatic patients under surveillance, patients undergoing elective surgery, and patients that have experienced rupture or dissection. By including patients at different stages of aneurysm growth it will be possible to determine if peak wall stress, the rupture risk index, or maximum diameter can meaningfully differentiate between the groups. Finally, for two of the five patients (Patients 2 and 3) we did not have access to patient specific intraluminal blood pressure and used instead mean diastolic and systolic arterial pressures of $80 \mathrm{mmHg}(10.6 \mathrm{kPa})$ and $120 \mathrm{mmHg}(16 \mathrm{kPa})$. Since the patients were not hypertensive, we expect that this was a reasonable approximation of the blood pressure.

\section{Conclusion}

In this work, we developed and applied a novel methodology for identification of patient specific wall stress distributions and retrospective rupture risk analysis. Using patient specific geometries, material properties, and wall strengths, we estimated the risk of rupture for five patients on the day of their surgical intervention. To translate these predictions to the clinical setting, we plan to improve the methodology by obtaining patient specific mechanical properties non-invasively from ECG-gated dynamic CT images combined with 4D MRI (Weigang et al., 2008). Finite element models generated using patient specific geometries and mechanical properties will eventually provide acceptable predictions of the wall stress distribution in the ATAA. To provide truly reliable estimates of rupture risk, these stress predictions must also be combined with a non-invasive method to estimate wall strength. To accomplish this, we plan to collect data on the rupture properties of more than 100 ATAA samples. The mechanical data will be combined with demographic data to form a rupture stress estimate similar to the model developed by Vande Geest and colleagues (Vande Geest et al., 2006a).

\section{Acknowledgements}

Dr. Frances M. Davis was supported by the Whitaker International Scholars Program. 


\section{References:}

Carew, T.E., Vaishnav, R.N., Patel, D.J., 1968. Compressibility of the Arterial Wall. Circ. Res. 23, 61-68.

Chau, K.H., Elefteriades, J.A., 2013. Natural history of thoracic aortic aneurysms: size matters, plus moving beyond size. Prog. Cardiovasc. Dis. 56, 74-80.

Choudhury, N., Bouchot, O., Rouleau, L., Tremblay, D., Cartier, R., Butany, J., Mongrain, R., Leask, R.L., 2009. Local mechanical and structural properties of healthy and diseased human ascending aorta tissue. Cardiovasc. Pathol. 18, 83-91.

Coady, M.A., Rizzo, J.A., Hammond, G.L., Kopf, G.S., Elefteriades, J.A., 1999. Surgical Intervention Criteria for Thoracic Aortic Aneurysms : A Study of Growth Rates and Complications. Ann. Thorac. Surg. 67, 1922-1926.

Coady, M.A., Rizzo, J.A., Hammond, G.L., Mandapati, D., Darr, U., Kopf, G.S., Elefteriades, J.A., 1997. What is the appropriate size criterion for resection of thoracic aortic aneurysms? J. Thorac. Cardiovasc. Surg. 113, 476-91; discussion 489-91.

Davies, R.R., Goldstein, L.J., Coady, M.A., Tittle, S.L., Rizzo, J.A., Kopf, G.S., Elefteriades, J.A., 2002. Yearly Rupture or Dissection Rates for Thoracic Aortic Aneurysms : Simple Prediction Based on Size. Ann. Thorac. Surg. 73, 17-28.

Davis, F.M., Luo, Y., Avril, S., Duprey, A., Lu, J., 2015. Pointwise characterization of the elastic properties of planar soft tissues: application to ascending thoracic aneurysms. Biomech. Model. Mechanobiol.

Demiray, H., 1972. A note on the elasticity of soft biological tissues. J. Biomech. 5, 309-311.

Doyle, B.J., Callanan, A., Grace, P.A., Kavanagh, E.G., 2013. On the influence of patientspecific material properties in computational simulations: a case study of a large ruptured abdominal aortic aneurysm. Int. j. numer. method. biomed. eng. 29, 150-64.

Duprey, A., Khanafer, K., Schlicht, M., Avril, S., Williams, D., Berguer, R., 2010. In Vitro Characterisation of Physiological and Maximum Elastic Modulus of Ascending Thoracic Aortic Aneurysms Using Uniaxial Tensile Testing. Eur. J. Vasc. Endovasc. Surg. 39, 700-707.

Elefteriades, J.A., Farkas, E.A., 2010. Thoracic aortic aneurysm clinically pertinent controversies and uncertainties. J. Am. Coll. Cardiol. 55, 841-57.

Fillinger, M.F., Marra, S.P., Raghavan, M.L., Kennedy, F.E., 2003. Prediction of rupture risk in abdominal aortic aneurysm during observation: wall stress versus diameter. J. Vasc. Surg. 37, 724-32.

Gasser, T.C., Auer, M., Labruto, F., Swedenborg, J., Roy, J., 2010. Biomechanical rupture risk assessment of abdominal aortic aneurysms: model complexity versus predictability of finite element simulations. Eur. J. Vasc. Endovasc. Surg. 40, 176-85. 
Iliopoulos, D.C., Deveja, R.P., Kritharis, E.P., Perrea, D., Sionis, G.D., Toutouzas, K., Stefanadis, C., Sokolis, D.P., 2009a. Regional and directional variations in the mechanical properties of ascending thoracic aortic aneurysms. Med. Eng. Phys. 31, 1-9.

Iliopoulos, D.C., Kritharis, E.P., Giagini, A.T., Papadodima, S.A., Sokolis, D.P., 2009b. Ascending thoracic aortic aneurysms are associated with compositional remodeling and vessel stiffening but not weakening in age-matched subjects. J. Thorac. Cardiovasc. Surg. 137, 101-109.

Johansson, G., Markström, U., Swedenborg, J., 1995. Ruptured thoracic aortic aneurysms: a study of incidence and mortality rates. J. Vasc. Surg. 21, 985-8.

Juvonen, T., Ergin, M.A., Galla, J.D., Lansman, S.L., Nguyen, K.H., Mccullough, J.N., Levy, D., de Asla, R.A., Bodian, C.A., Griepp, R.B., 1997. Prospective Study of the Natural History of Thoracic Aortic Aneurysms. Ann. Thorac. Surg. 4975, 1533-45.

Lee, K., Zhu, J., Shum, J., Zhang, Y., Muluk, S.C., Chandra, A., Eskandari, M.K., Finol, E.A., 2013. Surface curvature as a classifier of abdominal aortic aneurysms: a comparative analysis. Ann. Biomed. Eng. 41, 562-76.

Marra, S.P., Kennedy, F.E., Kinkaid, J.N., Fillinger, M.F., 2006. Elastic and rupture properties of porcine aortic tissue measured using inflation testing. Cardiovasc. Eng. 6, $123-31$.

Martin, C., Sun, W., Pham, T., Elefteriades, J., 2013. Predictive biomechanical analysis of ascending aortic aneurysm rupture potential. Acta Biomater. 9, 9392-400.

Martínez-Martínez, F., Rupérez, M.J., Martín-Guerrero, J.D., Monserrat, C., Lago, M. a, Pareja, E., Brugger, S., López-Andújar, R., 2013. Estimation of the elastic parameters of human liver biomechanical models by means of medical images and evolutionary computation. Comput. Methods Programs Biomed. 111, 537-49.

Martufi, G., Gasser, T.C., Appoo, J.J., Di Martino, E.S., 2014. Mechano-biology in the thoracic aortic aneurysm: a review and case study. Biomech. Model. Mechanobiol. 13, 917-28.

Peattie, R.A., Asbury, C.L., Bluth, E.I., Riehle, T.J., 1996. Steady flow in models of abdominal aortic aneurysms. Part II: Wall stresses and their implication for in vivo thrombosis and rupture. J. Ultrasound Med. 15, 689-696.

Peattie, R.A., Riehle, T.J., Bluth, E.I., 2004. Pulsatile Flow in Fusiform Models of Abdominal Aortic Aneurysms: Flow Fields, Velocity Patterns and Flow-Induced Wall Stresses. J. Biomech. Eng. 126, 438.

Polzer, S., Gasser, T.C., Bursa, J., Staffa, R., Vlachovsky, R., Man, V., Skacel, P., 2013. Importance of material model in wall stress prediction in abdominal aortic aneurysms. Med. Eng. Phys. 35, 1282-9.

Ramanath, V.S., Oh, J.K., Sundt, T.M., Eagle, K.A., 2009. Acute aortic syndromes and thoracic aortic aneurysm. Mayo Clin. Proc. 84, 465-81. 
Raut, S.S., Chandra, S., Shum, J., Finol, E.A., 2013a. The role of geometric and biomechanical factors in abdominal aortic aneurysm rupture risk assessment. Ann. Biomed. Eng. 41, 1459-77.

Raut, S.S., Jana, A., De Oliveira, V., Muluk, S.C., Finol, E.A., 2013b. The importance of patient-specific regionally varying wall thickness in abdominal aortic aneurysm biomechanics. J. Biomech. Eng. 135, 81010.

Reeps, C., Gee, M., Maier, A., Gurdan, M., Eckstein, H.-H., Wall, W. a, 2010. The impact of model assumptions on results of computational mechanics in abdominal aortic aneurysm. J. Vasc. Surg. 51, 679-88.

Riveros, F., Chandra, S., Finol, E.A., Gasser, T.C., Jose, F., 2013. A pull-back algorithm to determine the unloaded vascular geometry in anisotropic hyperelastic AAA passive mechanics. Ann. Biomedial Eng. 41, 694-708.

Romo, A., Badel, P., Duprey, A., Favre, J.-P., Avril, S., 2014. In vitro analysis of localized aneurysm rupture. J. Biomech. 47, 607-616.

Shang, E.K., Nathan, D.P., Sprinkle, S.R., Fairman, R.M., Bavaria, J.E., Gorman, R.C., Gorman, J.H., Jackson, B.M., 2013. Impact of wall thickness and saccular geometry on the computational wall stress of descending thoracic aortic aneurysms. Circulation 128, S157-62.

Shum, J., Martufi, G., Di Martino, E., Washington, C.B., Grisafi, J., Muluk, S.C., Finol, E.A., 2011. Quantitative assessment of abdominal aortic aneurysm geometry. Ann. Biomed. Eng. 39, 277-86.

Sundt, T.M., 2013. Indications for aortic aneurysmectomy: too many variables and not enough equations? J. Thorac. Cardiovasc. Surg. 145, S126-9.

Truijers, M., Pol, J.A., Schultzekool, L.J., van Sterkenburg, S.M., Fillinger, M.F., Blankensteijn, J.D., 2007. Wall stress analysis in small asymptomatic, symptomatic and ruptured abdominal aortic aneurysms. Eur. J. Vasc. Endovasc. Surg. 33, 401-7.

Vande Geest, J.P., Di Martino, E.S., Bohra, A., Makaroun, M.S., Vorp, D.A., 2006a. A biomechanics-based rupture potential index for abdominal aortic aneurysm risk assessment: demonstrative application. Ann. N. Y. Acad. Sci. 1085, 11-21.

Vande Geest, J.P., Sacks, M.S., Vorp, D.A., 2006b. The effects of aneurysm on the biaxial mechanical behavior of human abdominal aorta. J. Biomech. 39, 1324-34.

Vorp, D.A., 2007. Biomechanics of abdominal aortic aneurysm. J. Biomech. 40, 1887-1902.

Zhao, X., Chen, X., Lu, J., 2009. Pointwise Identification of Elastic Properties in Nonlinear Hyperelastic Membranes-Part II: Experimental Validation. J. Appl. Mech. 76, 061014. 
Tables and Figures:

Table 1 : Patient demographic information

\begin{tabular}{|c|c|c|c|c|}
\hline Patient ID & Sex/Age & $\begin{array}{l}\text { Pre-surgical CT } \\
\text { diameter (mm) }\end{array}$ & $\begin{array}{l}\text { Ex vivo } \\
\text { thickness }(\mathbf{m m})\end{array}$ & Pathologies \\
\hline 1 & $\mathrm{M} / 55$ & 55 & 2.38 & $\begin{array}{c}\text { Aortic insufficiency (AI), } \\
\text { bicuspid aortic valve }\end{array}$ \\
\hline 2 & $\mathrm{~F} / 76$ & 65 & 2.44 & AI \\
\hline 3 & $\mathrm{M} / 79$ & 52 & 1.76 & $\begin{array}{c}\text { AI, coronary artery disease, } \\
\text { myocardial infarction }\end{array}$ \\
\hline 4 & $\mathrm{M} / 40$ & 55 & 1.59 & AI, bicuspid aortic valve \\
\hline 5 & $\mathrm{M} / 72$ & 51 & 1.90 & $\begin{array}{c}\text { AI, coronary artery disease, } \\
\text { hypertension }\end{array}$ \\
\hline
\end{tabular}

Table 2 : Patient specific material properties and rupture stresses

\begin{tabular}{|c|c|c|c|c|}
\hline Patient ID & $\mathbf{D}_{\mathbf{1}}(\mathbf{k P a})$ & $\mathbf{D}_{\mathbf{2}}$ & Rupture Stress (MPa) & $\boldsymbol{\varepsilon}$ \\
\hline $\mathbf{1}$ & $8.38 \pm 1.12$ & $2.57 \pm 0.23$ & $1.05(\mathrm{n}=2)$ & 0.041 \\
\hline $\mathbf{2}$ & $1.68 \pm 0.28$ & $8.35 \pm 0.75$ & $1.31(\mathrm{n}=4)$ & 0.034 \\
\hline $\mathbf{3}$ & 4.15 & 13.30 & $0.95(\mathrm{n}=1)$ & 0.088 \\
\hline $\mathbf{4}$ & $10.96 \pm 0.25$ & $2.17 \pm 0.18$ & $2.33^{*}(\mathrm{n}=2)$ & 0.063 \\
\hline $\mathbf{5}$ & $9.64 \pm 2.16$ & $6.60 \pm 1.35$ & & $0.76^{*}(\mathrm{n}=2)$ \\
\hline
\end{tabular}

*The sample ruptured at the border. 

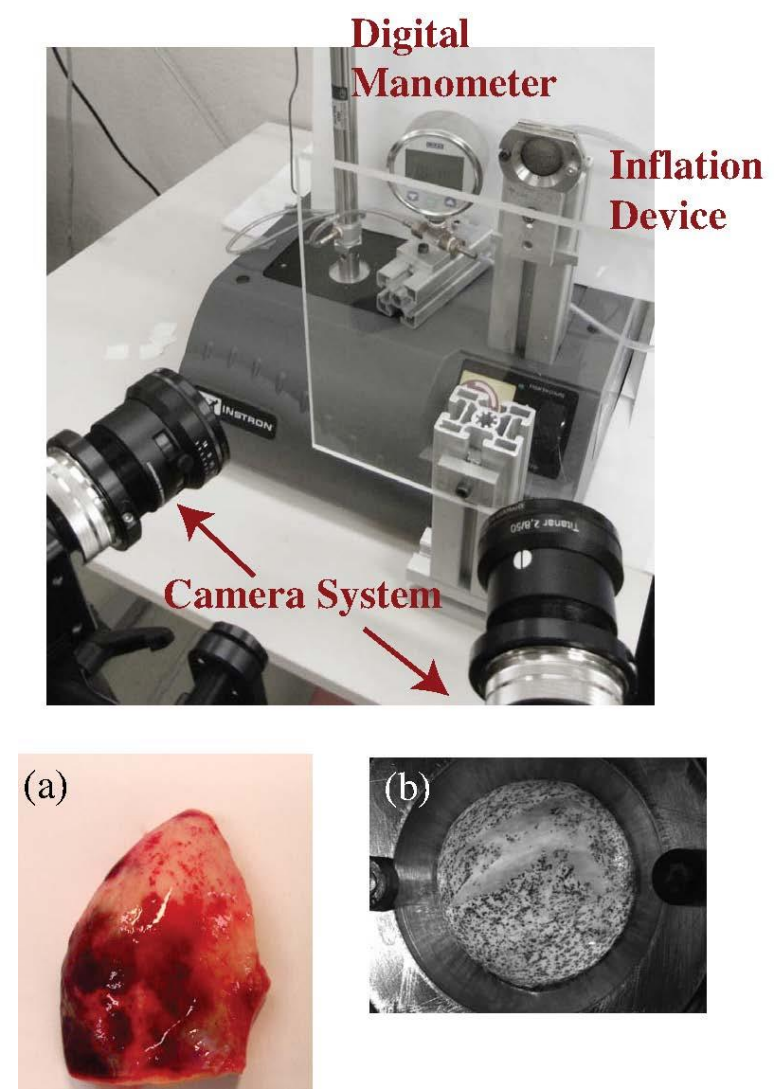

Figure 1: Bulge inflation test experimental setup and test sample (a) immediately after surgical resection and (b) after rupture in the bulge inflation device 


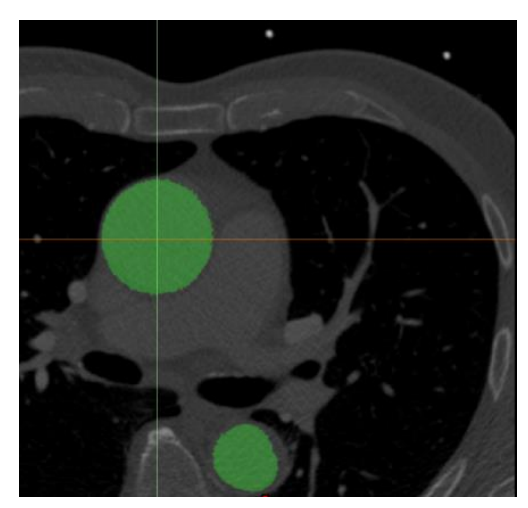

(a)

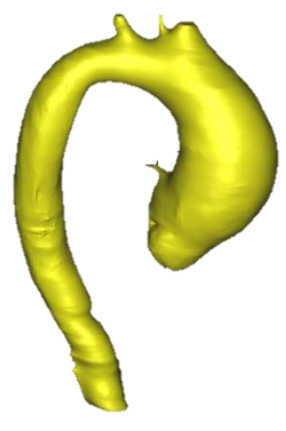

(b)

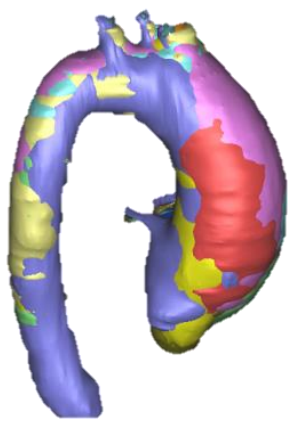

(c)

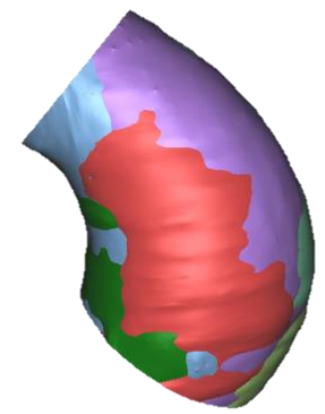

(d)

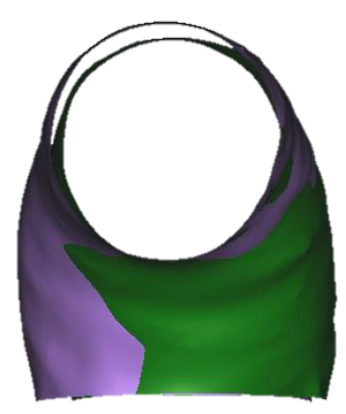

(e)

Figure 2 : Patient specific aneurysm geometry extraction. (a) DICOM CT image with the aorta in green. (b) Segmented aorta at a single phase in the cardiac cycle. (c) Segmented aorta at 10 different phases of the cardiac cycle (superimposed). (d) Aneurismal section of the aorta for 10 different phases of the cardiac cycle. (e)

Diastolic and systolic geometries of the ATAA identified from the volume change during the cardiac cycle (Fig. 6) 


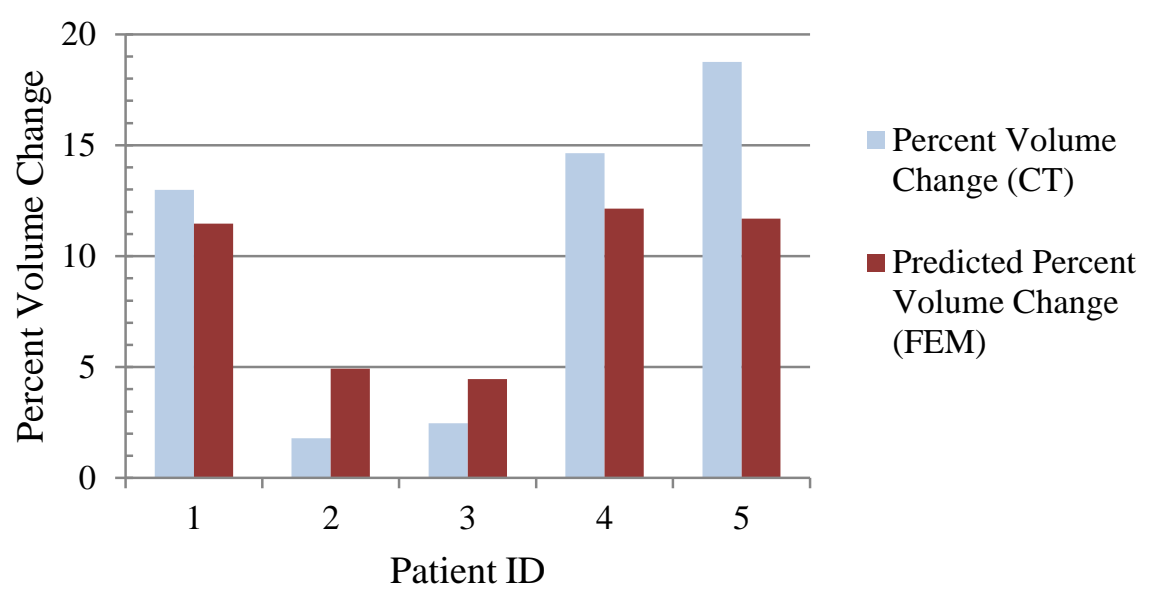

Figure 3: Comparison between actual (blue) and predicted (red) percent volume change of the aneurysm between diastole and systole for each patient. 


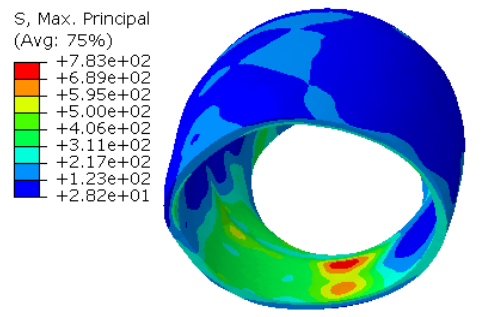

(a)

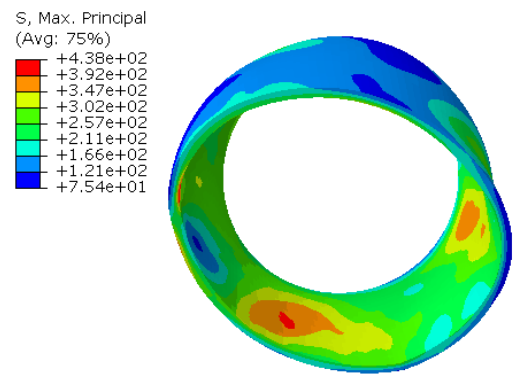

(c)

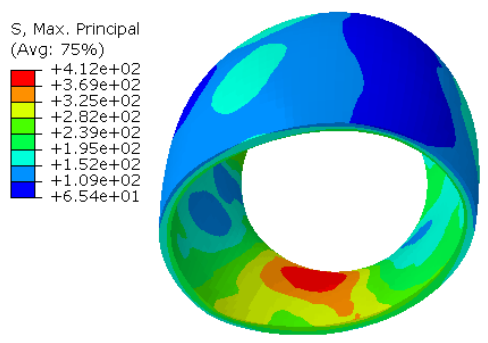

(e)

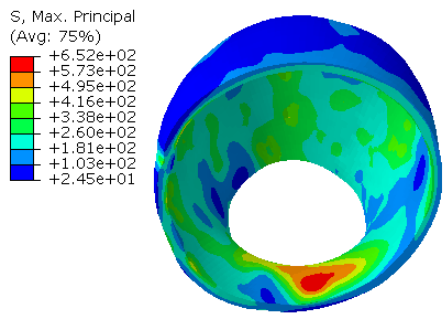

(b)

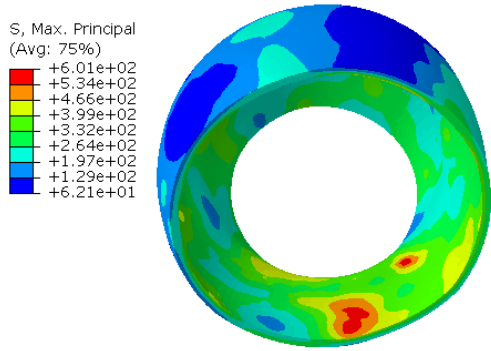

(d)

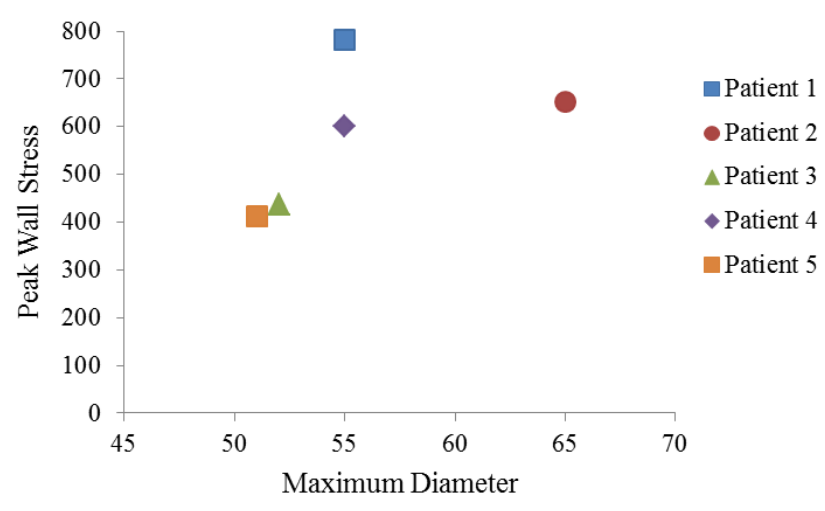

(f)

Figure 4: Principal stress in the aneurysm wall at a pressure for $15 \mathrm{kPa}$ for (a) Patient 1, (b) Patient 2, (c) Patient 3, (d) Patient 4, (e) Patient 5, and (f) plot of peak wall stress vs maximum aneurysm diameter $(\rho=0.53)$. The maximum wall stress for Patients 1-5 are 783, 652, 438, 601, and $412 \mathrm{kPa}$, respectively. 


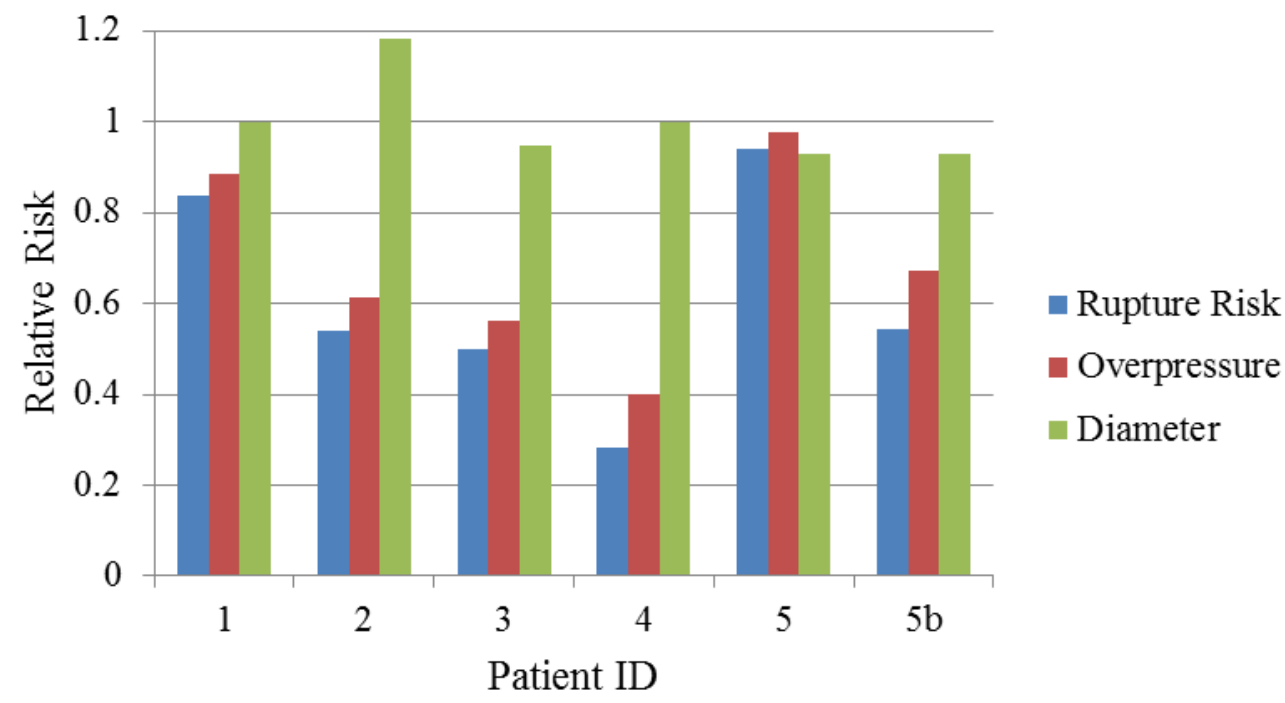

Figure 5: Comparison of the biomechanical and diameter based rupture risk assesments (a) rupture risk index (blue), (b) overpressure index (red), and (c) diameter index (green). The rupture risk at 5 is calculated using the high systolic pressure of $174 \mathrm{mmHg}$ and $5 \mathrm{~b}$ is found using the normal systolic pressure of $120 \mathrm{mmHg}$. 


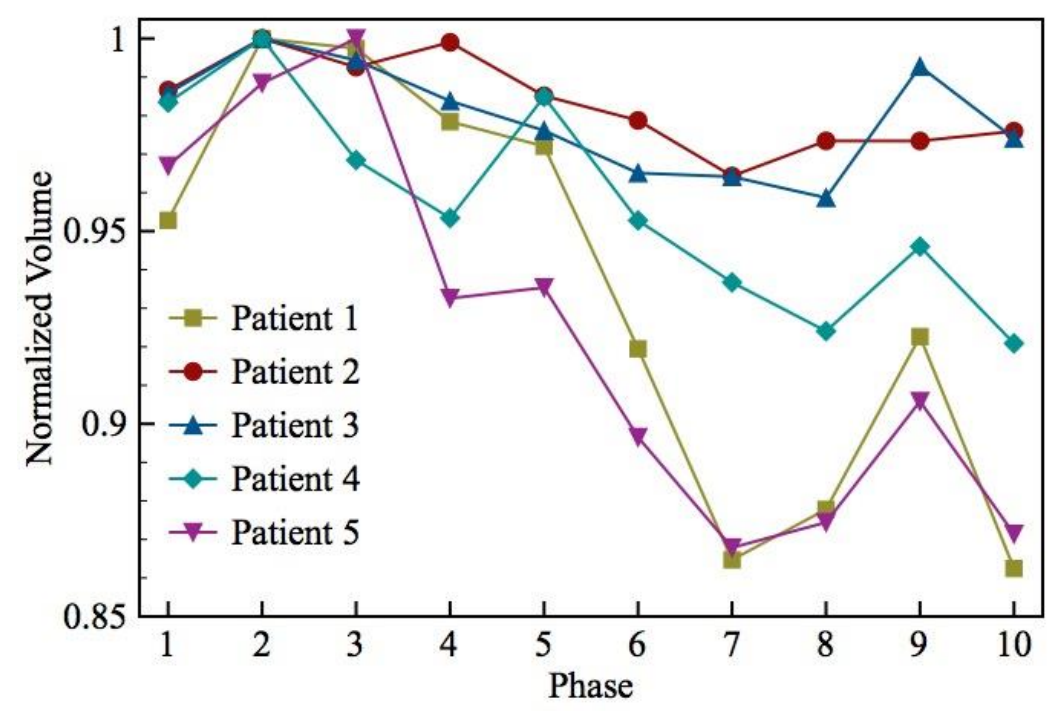

Figure 6: Volume variation during the cardiac cycle 


\section{Appendix}

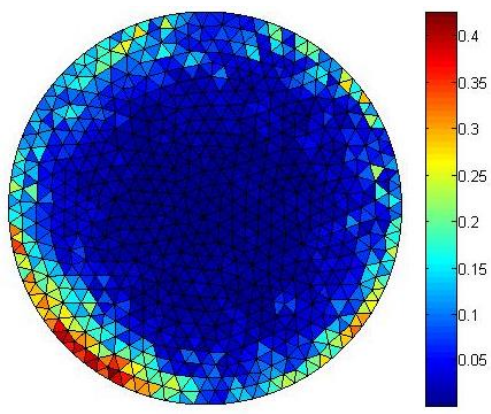

Patient 1

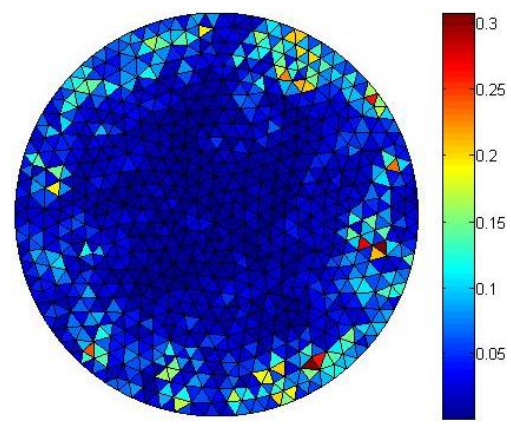

Patient 4

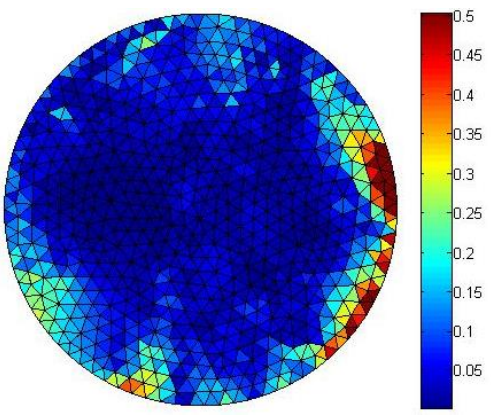

Patient 2

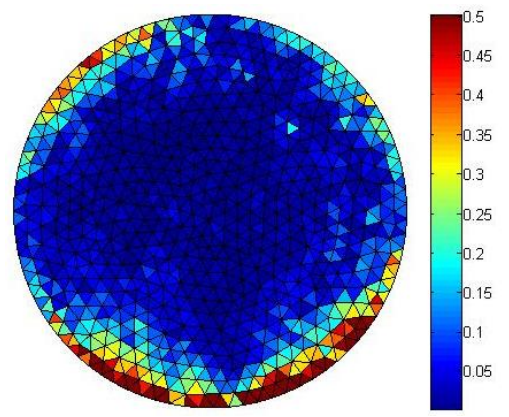

Patient 3

Figure S1: Map of the maximum co-axiality indicator for all the patients 
Table S1: Variation of the aneurysmal volume for each patient during the cardiac cycle.

\begin{tabular}{|c|c|c|c|}
\hline Patient & $\begin{array}{c}\text { CT diastolic } \\
\text { volume (mm3) }\end{array}$ & $\begin{array}{c}\text { CT systolic } \\
\text { volume (mm3) }\end{array}$ & $\begin{array}{c}\text { FEM systolic } \\
\text { volume (mm3) }\end{array}$ \\
\hline Patient 1 & 108145.73 & 122179.43 & 120549.40 \\
\hline Patient 2 & 145898.62 & 148528.18 & 153090.43 \\
\hline Patient 3 & 34288.73 & 35131.60 & 35817.13 \\
\hline Patient 4 & 70774.30 & 81134.05 & 79375.44 \\
\hline Patient 5 & 52277.81 & 62086.99 & 55142.78 \\
\hline
\end{tabular}




\begin{tabular}{|l|l|l|}
\hline & CT image geometry (diastolic geometry) \\
\hline Patient 1 & & \\
\hline Patient 2 & & \\
\hline Patient 3 & \\
\hline
\end{tabular}

Figure S2: Diastolic geometries and zero pressure geometries for each patient 


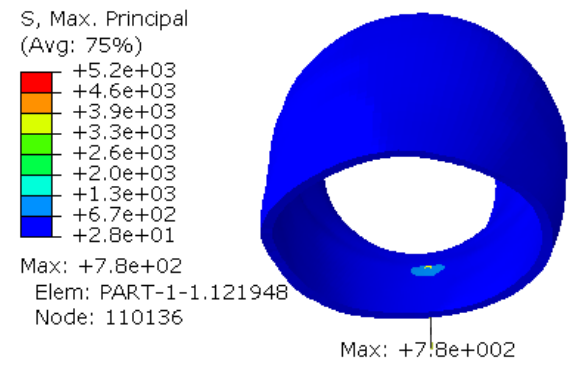

(a) $\mathrm{P}=15 \mathrm{kPa}$

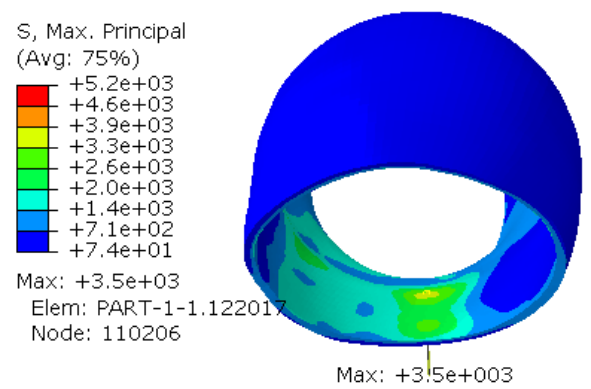

(c) $\mathrm{P}=45 \mathrm{kPa}$

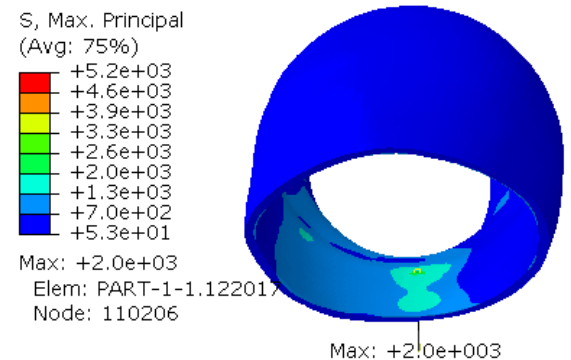

(b) $\mathrm{P}=30 \mathrm{kPa}$

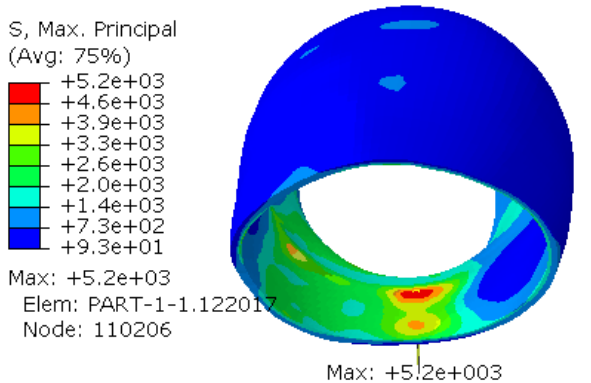

(d) $\mathrm{P}=60 \mathrm{kPa}$

Figure S3: Distribution of the principal stress for Patient 1 for an applied internal pressure of (a) $15 \mathrm{kPa}$, (b) 30

$\mathrm{kPa}$, (c) $45 \mathrm{kPa}$, and (d) $60 \mathrm{kPa}$. The location of maximum stress is labeled for each simulation. 


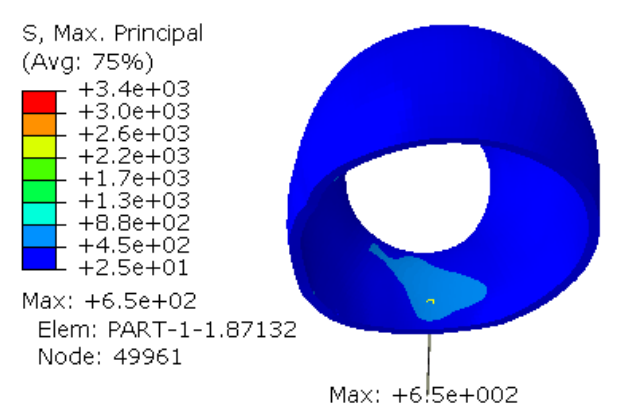

(a) $\mathrm{P}=15 \mathrm{kPa}$

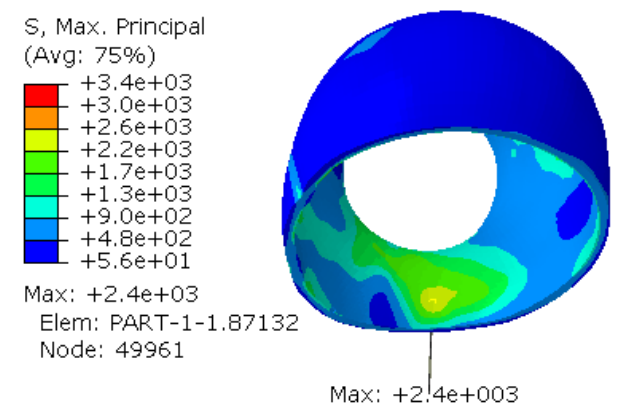

(c) $\mathrm{P}=45 \mathrm{kPa}$

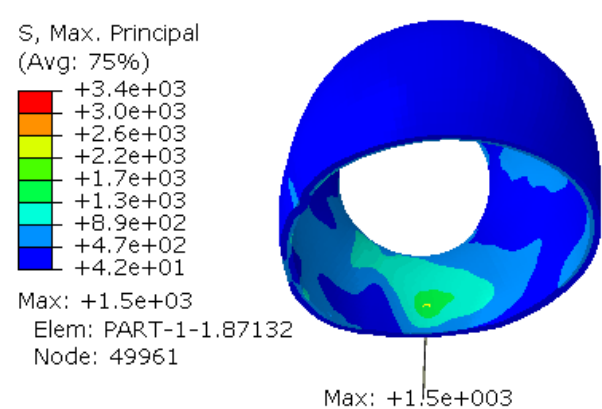

(b) $\mathrm{P}=30 \mathrm{kPa}$

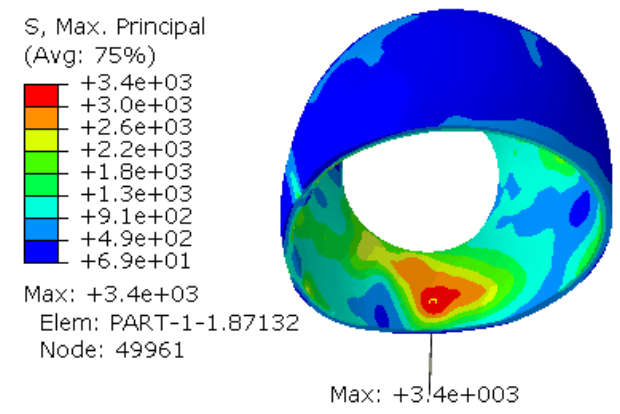

(d) $\mathrm{P}=60 \mathrm{kPa}$

Figure S4: Distribution of the principal stress for Patient 2 for an applied internal pressure of (a) $15 \mathrm{kPa}$, (b) 30

$\mathrm{kPa}$, (c) $45 \mathrm{kPa}$, and (d) $60 \mathrm{kPa}$. The location of maximum stress is labeled for each simulation. 


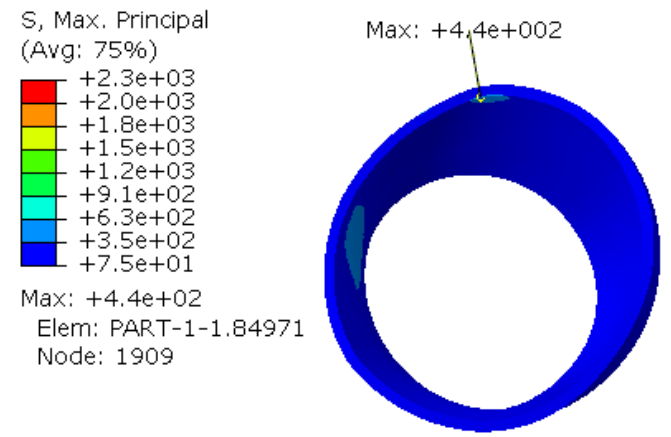

(a) $\mathrm{P}=15 \mathrm{kPa}$

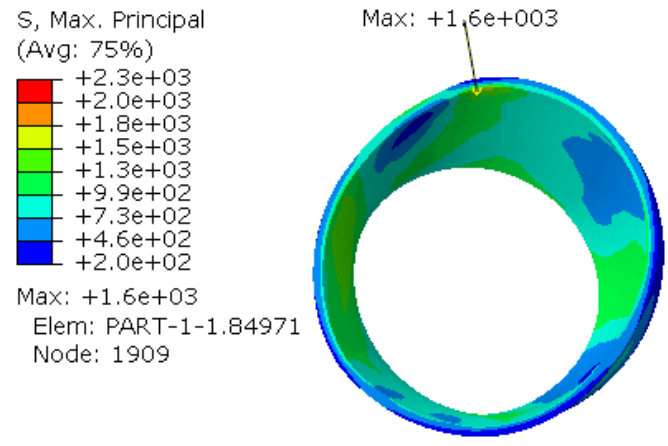

(c) $\mathrm{P}=45 \mathrm{kPa}$

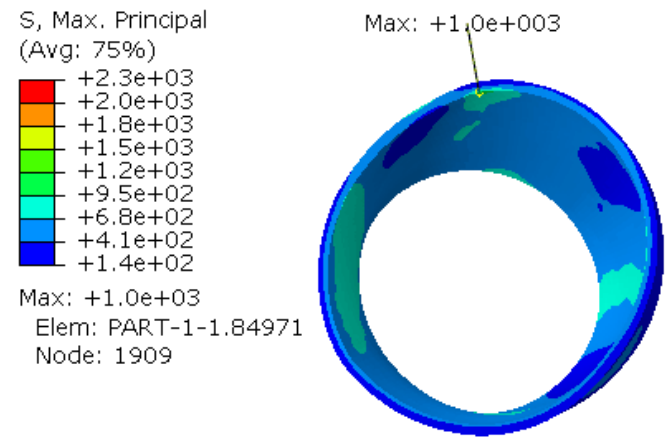

(b) $\mathrm{P}=30 \mathrm{kPa}$

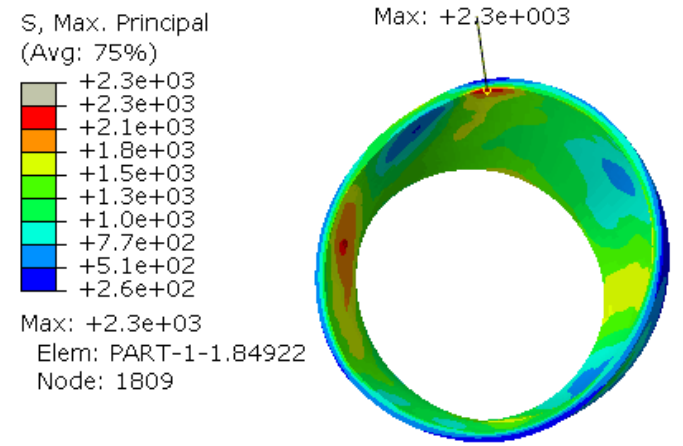

(d) $\mathrm{P}=60 \mathrm{kPa}$

Figure S5: Distribution of the principal stress for Patient 3 for an applied internal pressure of (a) $15 \mathrm{kPa}$, (b) 30

$\mathrm{kPa}$, (c) $45 \mathrm{kPa}$, and (d) $60 \mathrm{kPa}$. The location of maximum stress is labeled for each simulation. 


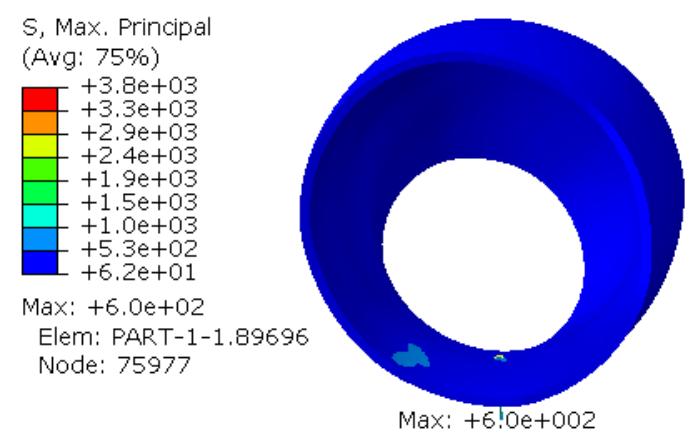

(a) $\mathrm{P}=15 \mathrm{kPa}$

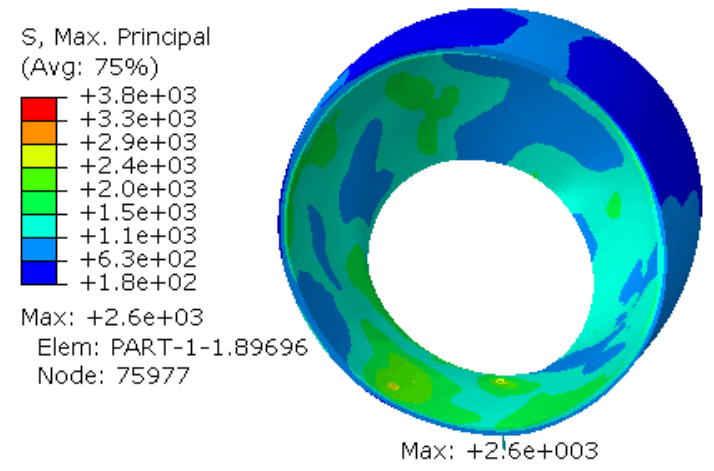

(c) $\mathrm{P}=45 \mathrm{kPa}$

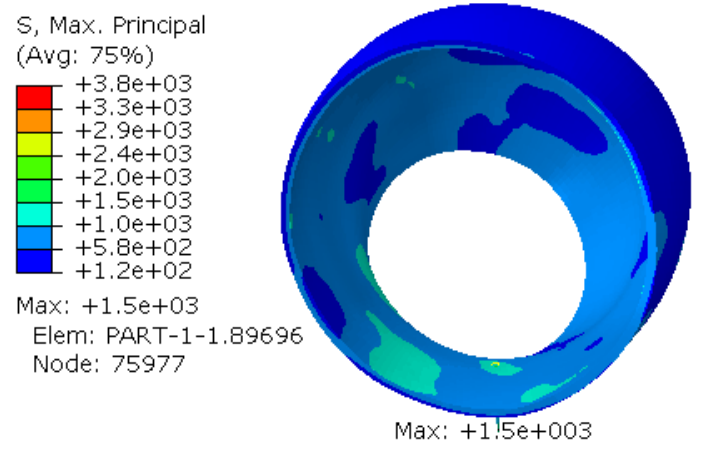

(b) $\mathrm{P}=30 \mathrm{kPa}$

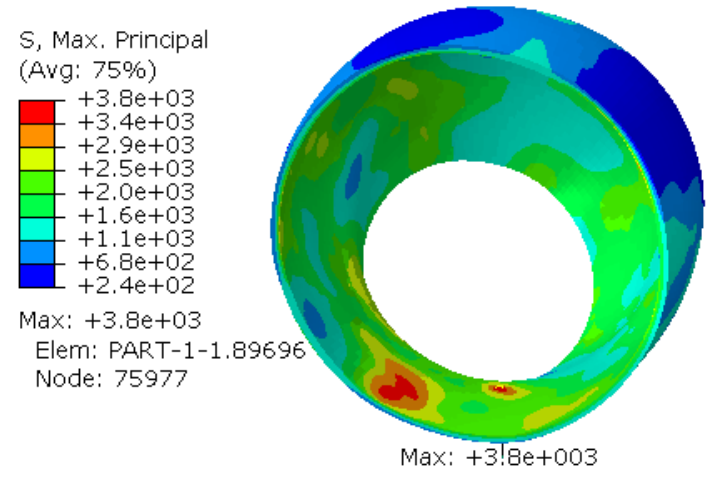

(d) $\mathrm{P}=60 \mathrm{kPa}$

Figure S6: Distribution of the principal stress for Patient 4 for an applied internal pressure of (a) $15 \mathrm{kPa}$, (b) 30

$\mathrm{kPa}$, (c) $45 \mathrm{kPa}$, and (d) $60 \mathrm{kPa}$. The location of maximum stress is labeled for each simulation. 
S, Max. Principal (Avg: 75\%)

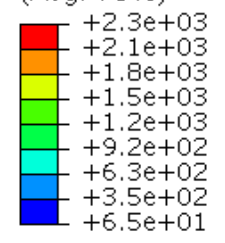

Elem: PART-1-1.84891

Node: 78874

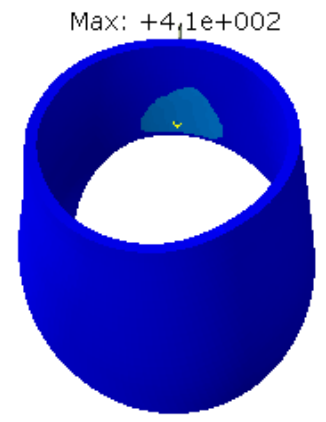

(a) $\mathrm{P}=15 \mathrm{kPa}$

S, Max. Principal (Avg: 75\%)
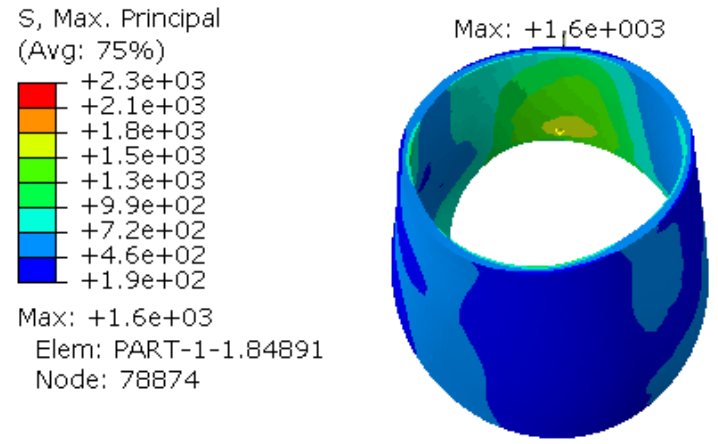

(c) $\mathrm{P}=45 \mathrm{kPa}$
S, Max. Principal

(Avg: 75\%)

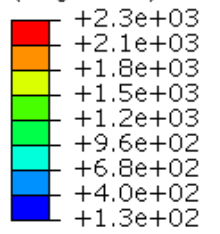

Max: $+9.9 \mathrm{e}+02$

Elem: PART-1-1.84891

Node: 78874

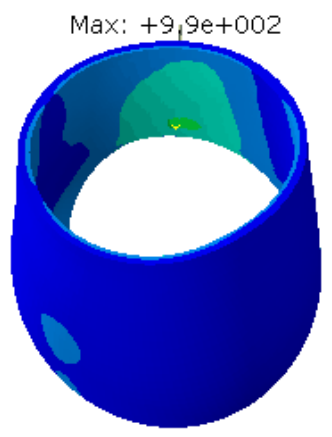

(b) $\mathrm{P}=30 \mathrm{kPa}$

S, Max. Principa (Avg: 75\%)

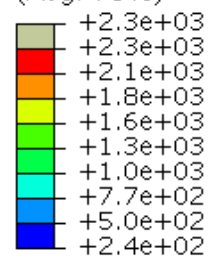

Max: $+2.3 e+03$

Elem: PART-1-1.84891 Node: 78874

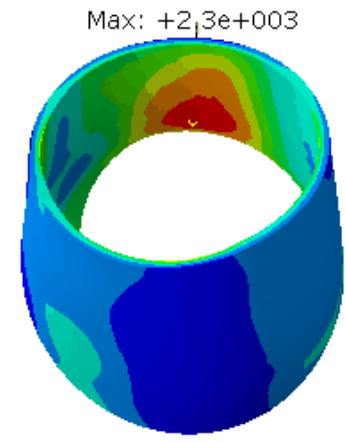

(d) $\mathrm{P}=60 \mathrm{kPa}$

Figure S7: Distribution of the principal stress for Patient 5 for an applied internal pressure of (a) $15 \mathrm{kPa}$, (b) 30

$\mathrm{kPa}$, (c) $45 \mathrm{kPa}$, and (d) $60 \mathrm{kPa}$. The location of maximum stress is labeled for each simulation. 